\title{
Road Safety Problems Associated with Increased use of e-Powered Personal Mobility Vehicles. Kaunas City Case Study
}

\author{
Jurgis Zagorskas*, Jonas Damidavičius \\ Department of Roads, Vilnius Gediminas Technical University, Saulètekio al. 11, 2510, Vilnius, Lithuania
}

Received 04 February 2020; accepted 31 March 2020

\begin{abstract}
Increased use of e-powered personal mobility vehicles is usually considered as a positive change; it is generally agreed that Personal Mobility Vehicles (PMVs) effectively and efficiently reduce negative environmental impacts of transport and improve the quality of life. There has been great technological progress made by all sectors in the field of personal mobility during the last decade. Use of PMV for micro-mobility is welcomed by market, consumers and governments and thus it is becoming increasingly popular in modern European society. New technology driven PMVs bring opportunities to their users, but at the same time create problems with street space sharing, road safety and traffic offenses. This study gives an overview of recent types of PMVs, offers some insights into the upcoming changes and challenges, and raises the discussion on themes related with increased use of e-powered personal transporters.
\end{abstract}

Keywords: urban sustainability, sustainable transportation, e-scooters, Personal Mobility Vehicles (PMV), Personal Light Electric Vehicles (LEV).

\section{Introduction}

Urban micro-mobility is taking fundamental changes in last decade. In dense urban environment, individual automobiles are being regarded as an unsustainable mode of transportation, and there is a shift in policy altogether with pragmatic considerations of society in the favor to eco-friendly, compact, light vehicles. Reduced automobile use can help to achieve many strategic targets - the cities can get rid of traffic jams, reduce greenhouse gas contribution, noise levels and improve air quality. While the number of vehicles is rapidly growing, the urban planners and transportation professionals are attempting to change people's travel mode selection to less energyintensive modes, alternative to walking, cycling and similar (Luo et al., 2020). Electrical power assisted personal mobility vehicles (e-PMVs) represent a relevant alternative - it is convenient, environment friendly mode of transportation for short trips in cities that can otherwise be clogged with traffic (Smith \& Schwieterman, 2018).

E-PMVs are cost-effective only on short-distance trips. Research on selection of travel modes shows that on trips between 0.8 and $3.2 \mathrm{~km}$, e-PMVs would be a particularly strong alternative to private automobiles (Smith \& Schwieterman, 2018). By filling this gap in mobility, e-PMVs have the potential to decrease the car use, but due to their higher relative cost on longer trips, e-PMVs would likely not result in significant diversion from public transit on longer-distance trips, particularly services operating to and from jobs. The use of e-PMVs on these longer journeys would likely be short connections to nearby transit stops (Smith \& Schwieterman, 2018).

According to market analytics (ReportBuyer, n.d.) global PMV market which includes scooters, walking aid, wheelchairs, and other is expected to grow at least till the year 2024 at a CAGR of $7.0 \%$. This number shows unprecedented potential. North America is now leading market of the PMV. Europe is now in second place and accounts for around 35\% of the PMV market share (Howe \& Bock, 2018).

Technological advancements undoubtedly revolutionize urban mobility, commuting, and our way of life. However, European society has reached a stage in which the fascination with technological innovations often results in their indiscriminate consumption (Martínez-Díaz et al., 2018). Shared e-scooters, to take it as an example, demonstrate that the introduction of technology implies some benefits to their users, but at the same time challenges other part of society. It is not enough to introduce the technology for mass consuming - the work must be conducted to make the most of its potential and prevent unfavorable outcomes, developing the adequate infrastructure for its proper usage.

\footnotetext{
${ }^{*}$ Corresponding author. E-mail: jurgis.zagorskas@vgtu.lt
} 
This paper raises the discussion on what measures are needed for reorganization of public and street space and overviews current policies on PMVs. Practical methods to identify problematic areas and predict PMV volumes are demonstrated. On a basis of presented methodology GIS tools for monitoring urban mobility changes and development of adequate infrastructure can be created. Such tools can be used by town and transportation planners to give supporting arguments for street space reorganization and implication of safety measures, as well as reconstruction of existing infrastructure to serve its future users in the better way.

\section{E-powered personal mobility vehicles}

E-PMV is a small personal vehicle that runs on electricity, powered by rechargeable lithium-ion vehicle batteries, and can travel at the speed of 20 to $60 \mathrm{~km} / \mathrm{h}$. This section of vehicles nowadays includes e-bicycle, e-scooter, monowheel, self-balancing devices, and other devices like e-skateboard. E-PMVs are frequently used for short-distance trips; they are becoming common in urban spaces. Research shows that they will dominate over the bicycle in the near future (Hasegawa et al., 2018). Future PMVs should be energy efficient, compact and light, easy to carry by hand, safe to drive, and easy to handle. Availability for sharing is also important; GPS tracking and use of smartphones enables this option (Beck et al., 2019).

With developed technologies - higher efficiency of electric motors, bigger capacity of batteries, integrated computer processor units, powerful lighting - e-PMVs have become strong competitors with traditional bicycle. Vehicles with electric assistance or fully e-powered vehicles can perform at the level of professional sportsman. Regular cyclist can generate up to $350 \mathrm{~W}$ power and average generated power on cruising speed is $100-160 \mathrm{~W}$. Person with high physical preparation (sportsman) can generate two times more power - instant 700-1000 W power and average 250-350 W power. Light electrical engines seen on modern e-bicycles, e-scooters and similar devices usually add or operate with the power of 350-1000 W. At the same time additional weight of the motor and batteries $(5-15 \mathrm{~kg})$ adds up, therefore the performance is less dramatic. E-power assistance increase the average travel speed two and more times from regular $12-17 \mathrm{~km} / \mathrm{h}$ bicycle speed to $25-50 \mathrm{~km} / \mathrm{h}$ e-motor speed. $50 \mathrm{~km} / \mathrm{h}$ speed is achieved only by most powerful devices of $750 \mathrm{~W}$ and more. In many cases for safety reasons the maximum speed is limited electronically.

Low-powered PTVs, in Europe also called mopeds or scooters, which are characterized by their maximum continuous rated power of no more than $4 \mathrm{~kW}$ and a maximum speed of $45 \mathrm{~km} / \mathrm{h}$, are defined in the EU-Regulation No 168/2013 as vehicle class L1e-B. To this category fall both motorcycles and PTVs. PTVs account for around 11$12 \%$ of the European passenger vehicle (Hardt \& Bogenberger, 2019).

Electric motors are being integrated into many types of leisure or sporting devices such as skateboards. Powered models come with modifications for smoother riding on uneven surfaces. These modifications have bigger inflatable wheels; they are more powerful and usually have wire or wireless remote control for the user to handle (Zagorskas \& Burinskienè, 2019).

\section{The impacts of PMVs on existing transport systems and adaptation of existing infrastructure for e-PMVs}

To be able to predict and respond to the changes in micro mobility it is important to understand and analyze the situations when users prefer PMVs instead of other transport means. It is popular between all age groups, from children, teenagers, to adults and elderly people. There are several reasons for this popularity: significant increase in fossil fuel prices; number of new inventions in electric motor efficiency, prolonged battery life and energy storage capacity; natural tendency of people to search for more convenient types and modes to travel in congested cities; increased micro-mobility without physical effort and other.

The distance for e-PMVs rides tend to be 4-5 km with estimated travel time between 15 and 20 minutes. The value differs from city to city (Howe \& Bock, 2018). Walking and cycling were traditionally the most common modes for micro-mobility, i.e. travelling short distances to the objects of daily needs. These modes are now being partially replaced by e-PMVs; the biggest part is taken by e-scooters.

Electric two-wheelers are now considered on the same category as bicycles. Bicycle network is the part of town transportation system and in great part it shares the same infrastructure with cars, pedestrian sidewalks, have the same travel origins and destinations. PMVs intend to share the same infrastructure with bicycles and cars pathways, parking space, etc. If part of car and bicycle users in future will change to PMVs, the remaining infrastructure will have some mismatches as Table 1 shows. The space which is now used by cars will free-up, and it can be reorganized to serve public transport, cars and e-PMVs together with bicycles. On the other hand the pavements and bicycle paths can become more crowded, but it will not create big problems, because of tiny space used by PMVs compared to automobile.

Recently with growing concern about public health and safety issues the revival of separating bicycle paths from motorized traffic is observed (Lawrence, 2016). The latest research topics show that separating bicycle lanes from main motorized traffic volumes for health reasons is important and recognized strategy (Luo et al., 2020; Jereb et al., 2018; Jack et al., 2018; Minet et al., 2018). The importance of relocating urban bike lanes to the calmer streets 
or nature predominated places is stressed by many researchers (Krenn et al., 2015). The bicycle networks are planned to be separated and moved away from heavy traffic to safer and healthier environments like unused riversides, parks and natural territories (Zalakeviciute et al., 2018; Otero et al., 2018; Gössling et al., 2019; Gongora et al., 2018). When implementing these measures it must be taken into consideration that more than half future users of these infrastructure will be e-PMV users, therefore new lanes must be designed according to requirements for higher speed and if possible with divisions for walking, low speed and higher speed lanes.

Table 1. Typical travel distances, speed and other parameters of different coexisting modes of transportation in European cities

\begin{tabular}{|l|c|c|c|c|c|}
\hline \multicolumn{1}{|c|}{ Travel mode } & $\begin{array}{c}\text { Typical trip } \\
\text { distance, } \\
\mathrm{km}\end{array}$ & $\begin{array}{c}\text { Average } \\
\text { travel speed, } \\
\mathrm{km} / \mathrm{h}\end{array}$ & $\begin{array}{c}\text { Used } \\
\mathrm{space} \\
\mathrm{m}^{2}\end{array}$ & $\begin{array}{c}\text { Maneuvering } \\
\text { radius in minimal } \\
\text { speed, } \mathrm{m}\end{array}$ & $\begin{array}{c}\text { Maneuvering } \\
\text { radius in cruising speed, } \\
\mathrm{m}\end{array}$ \\
\hline Walking & $<1.5$ & $4-6$ & $0.5-1.0$ & 0.0 & 0.5 \\
\hline E-bicycle & $0.5-15$ & $15-35$ & $1.2-1.7$ & $3.2-4.0$ & $12.0-18.0$ \\
\hline E-scooter (leg-kick type) & $0.5-5$ & $15-25$ & $0.8-1.2$ & $1.5-2.5$ & $1.5-2.5$ \\
\hline E-scooter (moped) & $1-20$ & $20-40$ & $1.2-2.0$ & $3.5-5.0$ & $16.0-20.0$ \\
\hline motorcycle & $1-20$ & $25-50$ & $1.5-2.2$ & $3.5-5.0$ & $16.0-20.0$ \\
\hline Public transport & $1-20$ & $30-35$ & $0.5-1.0$ & $6.0-9.0$ & $50.0-90.0$ \\
\hline Car & $2-35$ & $35-50$ & $5.0-12.0$ & $3.5-6.0$ & $40.0-50.0$ \\
\hline
\end{tabular}

At the same time in dense urban environments there is another popular measure of setting low speed zones $(30 \mathrm{~km} / \mathrm{h})$ when no division of space is needed; in this case driving the car becomes inconvenient. This measure is often used in town centers, historic districts or places with dense and narrow streets.

Researchers nowadays are focusing on studying cyclist and PMV user behavior and analyzing what makes these travel modes comfortable and pleasant with the aim to set the rules and afford friendlier environment for this kind of travel. During the past decades a number of methods have been endorsed for the selection of suitable bicycle routes including meta-heuristics, Q-learning algorithm and others (Lawrence \& Oxley, 2019; Lopez-Garcia \& Nebro, 2018; Chen et al., 2018; Pritchard, 2018). Many findings about cyclist preferences and behavior were collected from smartphones (Wu et al., 2018; Bernardi et al., 2018; Park \& Akar, 2019; Ghanayim \& Bekhor, 2018) and BIG-data sources (Zhang et al., 2019; Zeng, 2018; Zhang \& Mi, 2018). These methods were focused mostly on bicyclist travel route preference in existing network with the aim to predict the travel demand and highlight safety problems. Some of these findings could also be used to enhance solutions for developing the existing bicycle and PMV pathway infrastructure. The findings show that each individual cyclist or PMV user may prioritize differently between travel time and suitability when they choose a route, mostly they travel on two to three routes within the same origindestination pair and that perceived safety of the environment are the most important factor (Pritchard, 2018; Ehrgott et al., 2012; Majumdar \& Mitra, 2018).

There is significant increase in quality of pavements, crossings, safety measures, lighting and all other needed infrastructure to travel safely and comfortably. General urban population is starting to recognize and use recently developed pedestrian and bicycle infrastructure in an alternative, captivating and beneficial to them way. But in general many e-wheelers have disadvantage of small wheels that require very smooth surfaces and precisely leveled edges not yet present in many parts of European cities, especially in historic street pavements. It creates discomfort for the rider, increases number of fall-downs and consequent injuries. There is a big part of e-wheelers that are not so sensitive to pavement quality and have similar to e-bicycle wheel characteristics. Between these are e-mopeds, fattire e-scooters, monowheels, segways. To meet this requirement the existing bicycle lanes must be reconstructed to make smooth crossings with leveled edges; when reconstructing the pavements and bicycle paths, wearied-out surface has to be replaced to smoother option.

\section{PMVs and road safety}

Before permitting PMVs in shared environments, the impacts of the PMVs on the other users of the shared space should be properly evaluated, particularly from a safety perspective. Studies show that injuries occurring from these types of vehicles are significant and seem to be increasing (Boniface et al., 2011). E-scooters of leg-kick type cause more injuries than bicycles and other types of common e-wheelers (e-bicycles, e-mopeds, self-balancing devices) because of high speed in erect standing position and their availability throughout public sharing services for users without riding experience.

Popular research trend today is exploring the safety of bicycle (and at the same time PMV) routes (Boss et al., 2018; Prati et al., 2018; Pokorny \& Pitera, 2019). Many researchers put efforts in establishing the methods to explicitly address bicycle safety by reflecting urban conditions, and have found that many factors influence the 
safety, starting from traffic volume, lane width, population density, highway classification, presence of vertical grades, one-way streets, and truck routes (Lawrence, 2016). These urban conditions were taken into account to predict the severity of an injury that would result from a motor vehicle crash that can occur at a specific location (Allen-Munley et al., 2014; Rossetti et al., 2018; Aziz et al., 2018; Kang \& Fricker, 2018). The same methods and findings are applicable to e-PMV safety.

E-PMVs have impacts on other shared transportation space users also. These impacts are not limited to created danger from riding, the danger can be increased by taking the space provided for other vehicle types or improper parking. Table 2 shows general groups of impacts and their interconnection.

Table 2. Impacts of PMVs to other types of shared transportation space users

\begin{tabular}{|l|c|c|c|c|}
\hline & $\begin{array}{c}\text { Space } \\
\text { competitor }\end{array}$ & $\begin{array}{c}\text { Created danger to other } \\
\text { space users }\end{array}$ & $\begin{array}{c}\text { Danger from other } \\
\text { space users }\end{array}$ & $\begin{array}{c}\text { Sensitivity to improper } \\
\text { parking behaviors }\end{array}$ \\
\hline Pedestrians & high & high & low & high \\
\hline Car drivers & average & low & high & low \\
\hline Cyclists & low & low & average & average \\
\hline
\end{tabular}

In Singapore where the use of PMV has longer history (Advice, 2019) the conducted studies (King et al., 2019) show that motorized PMVs tripled the risk of severe injury and doubled the risk of requiring hospitalization, compared to non-motorized personal mobility devices, due to higher travelling speeds (Tan et al., 2019). Similar study from Korea shows that the number of injuries related to PMVs in 2017 raised three times compared to the year 2016 (51 vs. 14). Injuries to the head and neck region (67.7\%) were the most common, followed by the upper extremity (46.2\%) (Kim et al., 2018).

From the studies it can be concluded that further investigation into the risks of their use and training or practice, particularly for new or infrequent users (such as tourists), is needed. Protective equipment such as helmets should also be considered.

Several previous studies investigated the operational and safety aspects of PMVs in mixed traffic conditions. Most relevant study focuses on pedestrians' danger perception toward PMVs when interacting with them in shared spaces, it estimates a safety index called subjective danger index (SDI) (Hasegawa et al., 2018). Study explains that the safety of shared space users can be mainly classified into two categories: objective or physical safety and subjective or psychological safety. Psychological safety also has great importance and is one of the main reasons why general public is shocked by sudden invasion of e-PMVs.

The power of e-motor exceeds regular human power up to two-three times and can bring up serious danger if this vehicle is on the same path or lane with pedestrians or even regular cyclists. Changes in vehicle power change speed, momentum, maneuverability and driving trajectory parameters and future bicycle lanes or road infrastructure must be adapted to these changes. Table 3 shows recommended technical parameters for designing new pathways for use both with bicycle and e-PMVs.

Table 3. Recommended technical parameters for different design speeds

\begin{tabular}{|c|c|c|c|c|c|}
\hline $\begin{array}{c}\text { Speed, } \\
\mathrm{km} / \mathrm{h}\end{array}$ & $\begin{array}{c}\text { Minimum } \\
\text { horizontal } \\
\text { radius, } \mathrm{m}\end{array}$ & $\begin{array}{c}\text { Stopping sight } \\
\text { distance, } \mathrm{m}\end{array}$ & $\begin{array}{c}\text { Required set back in } \\
\text { crossings, } \mathrm{m}\end{array}$ & $\begin{array}{c}\text { Minimum separation } \\
\text { distance from pedestrians, } \\
\mathrm{m}\end{array}$ & $\begin{array}{c}\text { Minimum separation } \\
\text { distance from urban car } \\
\text { traffic }(50 \mathrm{~km} / \mathrm{h}), \mathrm{m}\end{array}$ \\
\hline 10 & 3.50 & 25 & 2 & Not required & 0.50 \\
\hline 30 & 25 & 50 & 4 & 1.50 & 1.50 \\
\hline 50 & 90 & 120 & 7 & 3 & Not required \\
\hline
\end{tabular}

When the pathways are designed for $30 \mathrm{~km} / \mathrm{h}$ speed the pedestrians are to be separated from these pathways by minimum separation distance of $1.50 \mathrm{~m}$. If in the future the pathways for e-PMVs would be designed for $50 \mathrm{~km} / \mathrm{h}$ speed cyclists must be separated from these paths.

Amongst the professionals there are proposals to limit the speed of shared e-scooters to safe maximum. As a more soft measure, limitations of speed can be easily put on many electrically driven devices with computer processor units. E-scooters can have imposed speed limits or even geo-fencing in dockless e-scooter applications to implicate safer speed zones in certain parts of the cities (geo-fencing reduces the speed of e-scooter automatically when it enters certain area). 


\section{Demonstration study}

City selected for demonstration of methods and techniques is typical European city with population 350,000, having its historical part near the confluence of two rivers and new, modern part of the city is in the upper terrace. In demonstration study we used Geographic Information System (GIS) techniques and some of the standard data sets available or easily collectable by survey analysis in most of Europe. Similar approach can be used for other locations beyond the demonstrated case study. The existing built-in GIS tools can be used to give for the transportation and town planners insights on mobility at micro scale. Proximity-based methods were used with data on the travel origindestination locations, street network and vehicle traffic. According to this data analysis locations of problematic areas were defined in broad sense and for particular street segments.

For broad analysis the city functions from transportation perspective were visualized. Tool used for this analysis is widely applied kernel density, used in GIS to visually represent concentration zones of objects in territory. To get result from kernel density analysis meaningful for transportation planning, concentrations of few types of objects living places, working places and other places where people are attracted were calculated. The kernel density analysis output is a floating-point raster with high values for concentration areas. The values are classified into five categories representing very low, low, moderate, high and very high concentrations of objects. All three types of concentration zones can be visualized on one map as seen in Figure 2.

Kernel density analysis gives general insights of most intensively used areas. In example shown in Figure 2 the greatest PMV use can be expected near the public attraction objects. Moderate use of PMVs can be expected along the streets leading from highly concentrated green areas to public attraction zones. The lowest intensity would produce concentration zones of working places, in this example the working places are scattered and doesn't result in great numbers (see Figure 1). Still it is important to take it into account, because main junctions connecting industry district to living districts would be burdened with PMVs on worst rush hours.

In represented case study the historical center and downtown are highlighted as the biggest public attraction object concentration zones, attracting from 800 to 1.000 people per hectare per day (pph). In these zones people are often using shared dockless e-scooters also. With added working and living places we can expect the use of PMVs with more than 250 instances per day in almost every street section of central area.

To make more precise kernel density analysis BIG DATA samples from Google or other similar services can be used. These data samples reveal the locations of most visited objects; by route analysis the heat-map can be created to visualize most popular and most vulnerable streets.

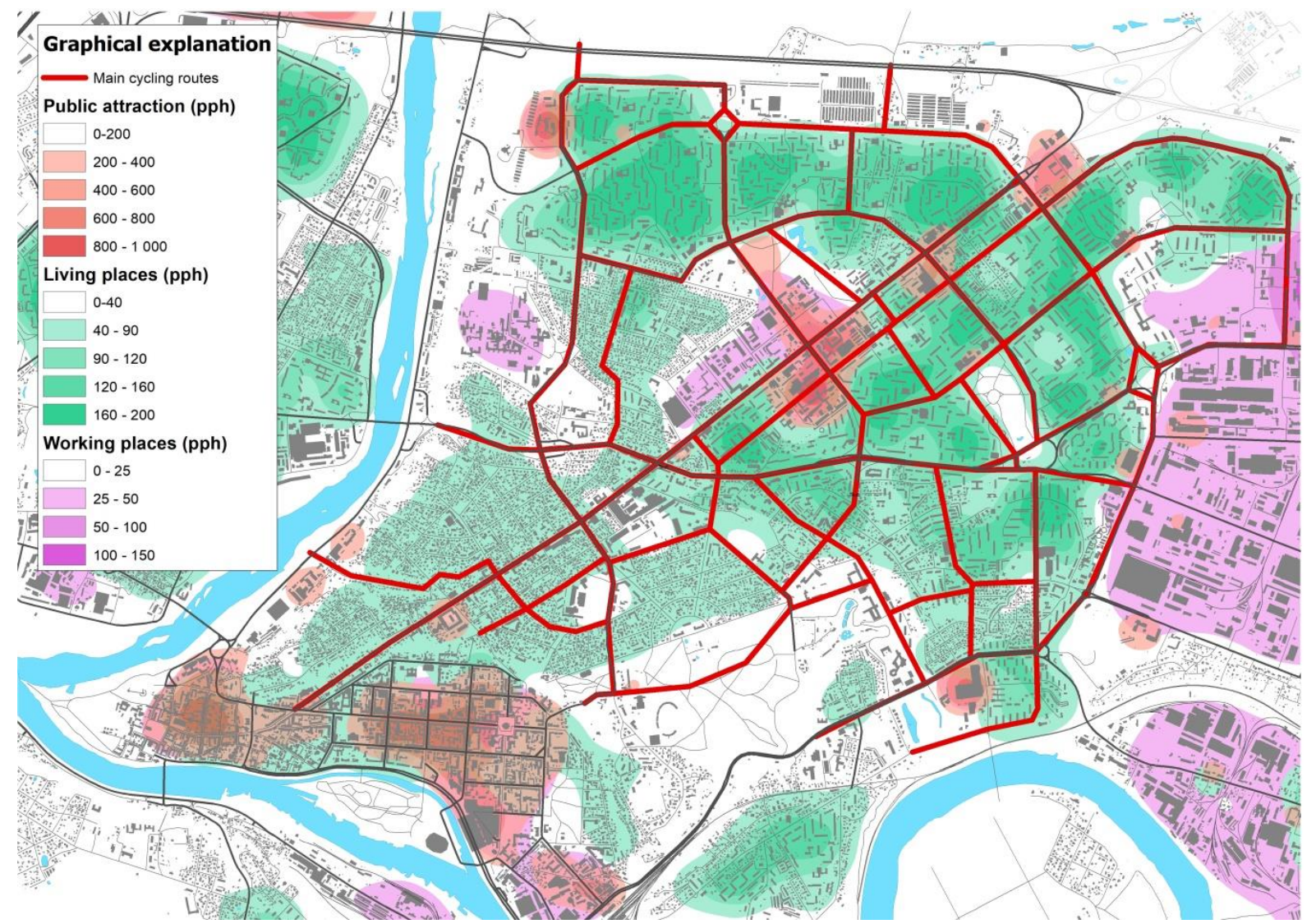

Figure 1. Results of performed proximity analysis (kernel density, search distance $50 \mathrm{~m}$ ) to visualize the functions and concentration zones of different types of objects important for personal mobility 
When making decisions on PMV infrastructure development or predicting PMV volumes many sources of available information can be helpful: useful data can be obtained from e-scooter sharing service providers (although it is limited to dockless e-scooters and does not include more frequent users who themselves own a PMV); other useful resource could be monitoring information obtained from municipality services; information on car and PMV traffic volumes (it can be taken from STRAVA heat-map or direct field observation data); speed of the traffic; path quality; information derived by space syntax analysis; street network density and connectivity; spectacularity; presence of sunshade and wind shields; exposure to nature elements, etc.

In demonstration study we used available data to make predictions on PMV volumes. The predictions were made based on influence by several factors:

- Usefulness of street segment: number of journeys from living to working objects, from living to public attraction objects, from working to public attraction objects generated by finding shortest paths using graph theory methods. It is straight-forward prediction method which comprises most of weight in used formula.

- Existing traffic intensity: bicycle traffic - positive effect; car traffic intensity - negative effect; presence of heavy traffic - negative effect.

- Street network characteristics: centrality of segment - positive effect; connectivity - positive effect.

- Comfort and environmental perception of user: presence of nature elements - positive effect; presence of sunshades, windshields - positive effect; presence of separated lanes - positive effect; quality of the pavements - positive effect; density of crossings - negative effect.

All the effects from these characteristics were summed for each street segment multiplied by weight coefficients and it resulted in predicted PMV traffic volumes seen in Figure 2. Street segments in core city in the historic part were all predicted greatest PMV volumes and for visualization the whole zone was marked as central zone with highest volumes.

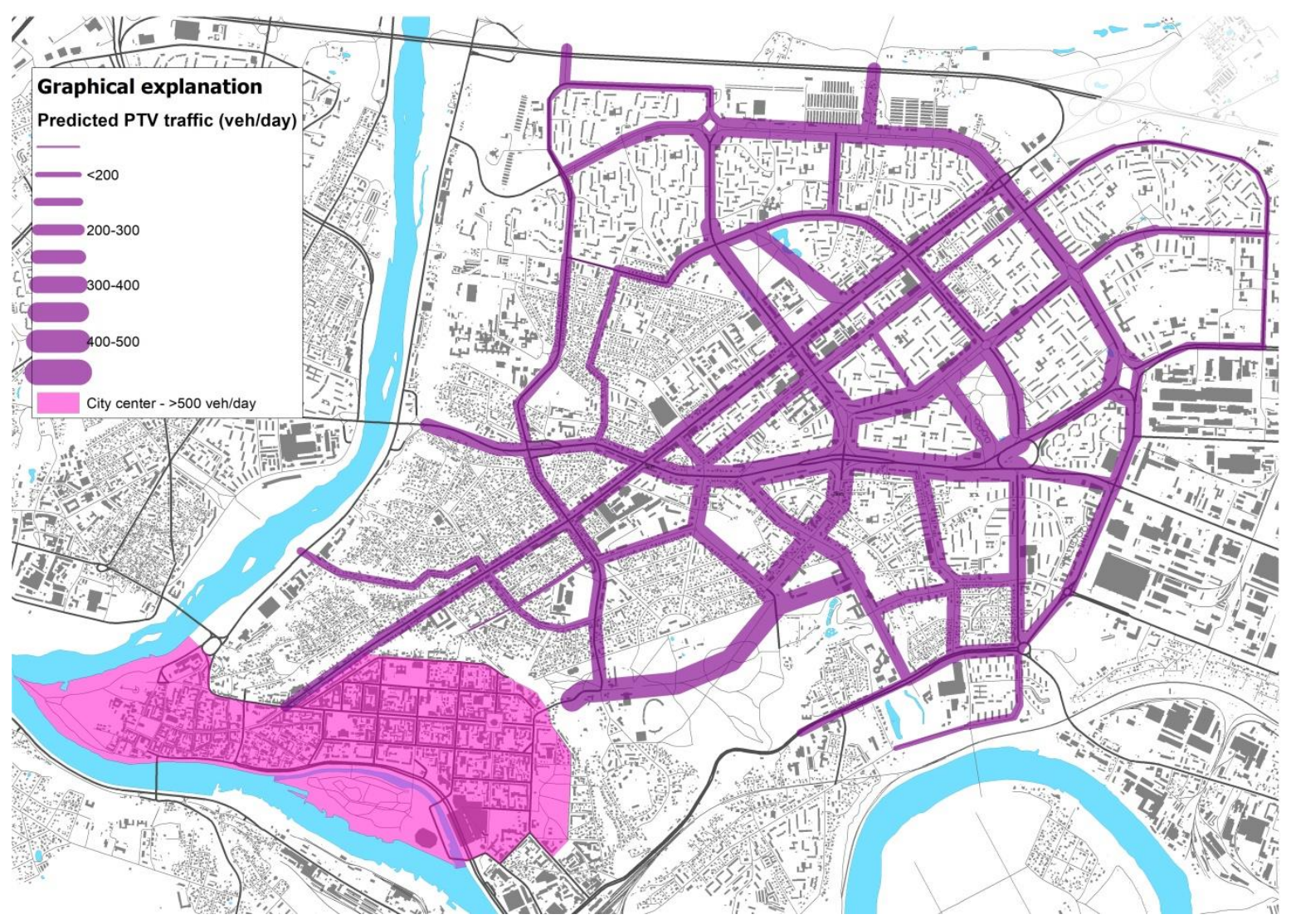

Figure 2. Predicted PMV traffic volumes in case study area (predictions made by mixed geostatistical, proximity methods and land use regression model)

Predicted PMV volumes give important insights. Demonstrated model shows the greatest volumes emerging on few main traffic corridors with intense car traffic, heavy traffic and constant overloading. In other places the great volumes are seen in connection going throw the green areas isolated from other transport. Prognosis for the central part of the city leaves no other alternatives than to switch to mixed use streets and limited speed zone, banning e-PMVs from two main pedestrian streets. 
Further investigation was made to define the street segments with highest possibility of conflicts between PMV users and car traffic. This investigation can serve for implementation of safety measures and give support to decisions on reorganization of street space. For this investigation additional data sources from GSM mobile devices were used to obtain additional information on locations of most frequently visited objects (shown in red points marks in Figure 3). This data with data on predicted volumes and other data from previous datasets were used to define the worst street segments with highest risk on PMV user safety.

The resultant map shows where the accidents can occur most frequently (Figure 3). In street sections with highest possibilities of conflict the best measure would be to separate PMV lanes, whereas in sections with lowest possibilities the measures must be taken to attract more users by making the lanes wide and comfortable, also separating them from pedestrians and nearby children playgrounds.

The map shown in Figure 3 reveals also the worst intersections where most of the accidents between PMV and car users can occur. These places on the map are the crossings of high possibility of conflict streets in close distance with conglomerations of visited objects. These intersections must be revised and reorganized primarily.

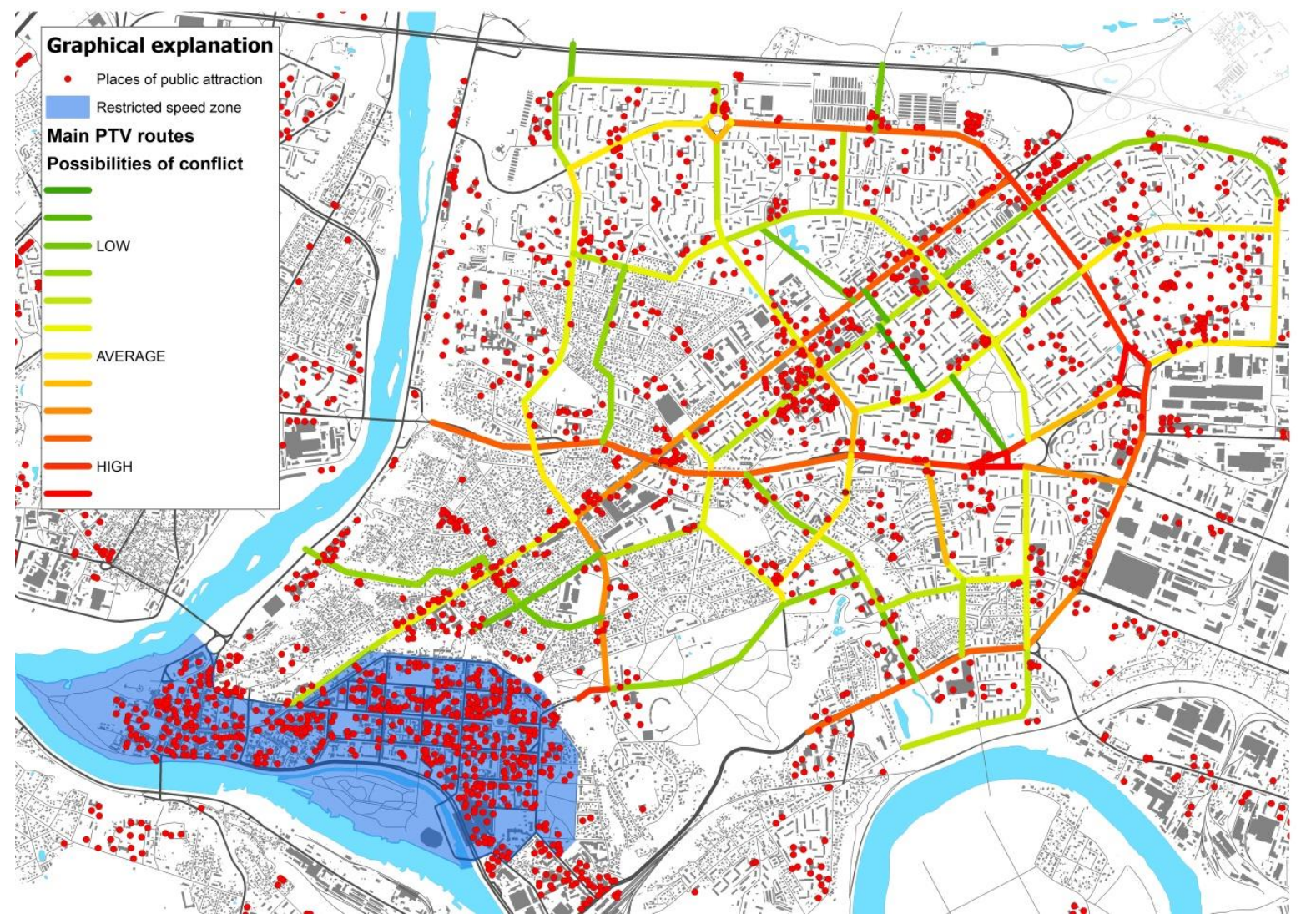

Figure 3. Predicted possibilities of conflict between e-PMV users and other traffic participants

\section{Current European policies on improper parking and riding behaviors}

European transportation planning policy in most of the countries is in favor of light transportation modes such as bicycles and vehicles under EU category of electric light vehicles (Frincu et al., 2017). Bicycling, walking and similar modes contribute zero greenhouse gas emissions, and therefore promoting these modes helps keep promises on climate change mitigation. As one of examples the EU HORIZON 2020 project ELVITEN (the full name of the project is "Electrified L-category Vehicles Integrated into Transport and Electricity Networks") is launched at 2017 (mostly in Italy) to demonstrate how electric light vehicles (EL-Vs) can be used in urban areas and be integrated into the existing transport network of six European cities. Another example is already finished Pro-E-Bike project (www.pro-e-bike.org), funded within the Intelligent Energy Europe programme. Project investigated the potentialities of e-bicycles and e-scooters, for goods delivering and services provision in urban areas (Nocerino et al., 2016).

European cities are relying on rules previously made for bicycles, rather than ones that take into account the unique aspects of e-PMVs. In most European countries the user needs neither a driver's license nor a helmet to use a scooter-share vehicle. In many southern countries (Italy, France, Spain, etc.) there's also the long-standing habit of using mopeds, which is making the idea of low-powered motor vehicles habitual for locals. 
However, the experiments made in European cities show that the implementation of e-PMVs is complicated. Public surveys show that e-scooters particularly elicit bad emotional response from society. E-scooters are new type of vehicle and gained popularity so quickly that they are largely unregulated. Appearing regulations are focused more on the scooter companies than users (Anderson-Hall et al., 2019). What is happening now is that the private companies are profiting off of taxpayers' investment - sidewalks - and making them less useful for residents. In response to that many e-scooter sharing initiatives were restricted: France have banned electric scooters from pavements in September 2019 to stop them from invading pedestrian areas (Paris, 2019); in December 2018, Madrid city government ordered main operator companies to remove their scooters from the streets, saying they had failed to comply with rules that determine which areas the scooters are allowed to operate in (Madrid, 2019) while Spanish tourist hotspot Barcelona has banned scooter rental services completely (Diputació Barcelona, 2019); Berlin's city hall has also drawn up tough new rules for e-scooters (BerlinOnline, n.d.). (Marcus, 2019) To deal with improper parking and riding behavior in Paris, anyone riding any type of e-PMV on the pavement is fined 135 euros from September 2019 (Paris, 2019). E-PMVs have to use the street or dedicated cycling paths. Paris officials plan to regulate the use of e-scooters with fines for riding on the sidewalks, designated parking spots and an annual fee for escooter operator companies. Every upcoming year Paris municipality will create 2.500 new parking spaces for escooters (AFP, 2019). Several European cities already provide dedicated areas for scooter parking (ePilot Mobility GmbH, 2019; Dimitrova, 2019).

Some lessons can be learned from USA experience over last two years (John MacArthur, 2014) - city governments of New York, Los Angeles, San Francisco, San Antonio, Austin, San Diego, Atlanta, Portland, Oregon had increased regulations for the e-scooters and e-bikes that have crowded sidewalks in the urban cores. Municipalities are starting to put light regulations of minimum rider age of 16, banning the vehicles from the important recreational areas and removing them from places where they are blocking ramps for wheelchair users (National Conference of State Legislatures, 2020).

There can be different measures to deal with arising problems. From one side e-wheelers can be promoted as micro-mobility revolution that serves the general public but from other side it can be restricted due to safety issues.

\section{Conclusions and discussion}

There has been great technological progress in e-PMV sector. Traditionally in European cities bicycle was serving great part (15-45\%) of short local trips, but now big part of these trips is takes by PMVs. Added electric power assistance helps to cover bigger distances, ride at higher speed, and cope with natural barriers like big inclines, windy, hilly areas.

Use of e-PMVs can lead to a cleaner, more sustainable future where e-powered fast and compact vehicles would be the primary mode of transportation but it can also have negative side effects: decreased road safety for PMV users themselves and other traffic participants; misuse of easily affordable dockless devices; environmental problems - mass e-scooter graveyards and discarded bike-share bicycles recently seen in China (Zuev et al., 2019).

\section{Potential development of infrastructure for e-PTVs}

The development of PMV industry is bringing many changes in the mobility behavior. The power of e-motor exceeds regular human power up to two-three times and can bring up serious danger if this vehicle shares the same street space with pedestrians or cyclists. Added vehicle power change speed, momentum, maneuverability and driving trajectory parameters. Future bicycle lanes and infrastructure must reflect these changes. To develop infrastructure the first step should be to localize the most problematic street sections and crossings. For this purpose most fit are demonstrated methods: GIS kernel density, geo-statistical and proximity analysis, land use regression models.

The speed of e-PMVs is greater than bicycle and can reach $50 \mathrm{~km} / \mathrm{h}$. This fact creates implications with street space sharing and increases chances for accidents to happen. The straight forward solution is to separate transportation modes by providing isolated space for pedestrians, bicyclists and e-PMVs at speed up to $30 \mathrm{~km} / \mathrm{h}$, adding separated lanes for e-bicycles and e-PMVs with speed higher than $30 \mathrm{~km} / \mathrm{h}$. But there can be many situations where this measure cannot be implemented. In such cases e-PMVs can share the same space with public transport if public transport lanes are separated. Another option is to allow e-PMVs use all the street space provided for cars in restricted $30 \mathrm{~km} / \mathrm{h}$ speed zones.

Demonstrated methods to localize problematic areas and predict PMV volumes give the general idea based on which GIS tools for monitoring urban mobility changes and development of adequate infrastructure can be created. Such tools can be used by town and transportation planners and provide supporting arguments for street space reorganization and reconstruction, implication of safety measures.

\section{Suggestions for policy-makers}

Various policy measures can be applied to restrict and regulate the use of e-PMVs. By now European cities are relying on rules previously created for bicycles, without taking into account the unique aspects of e-PMVs. In most 
European countries the user needs neither a driver's license nor a helmet to use e-PMV. This situation must be corrected primarily. Then the accidents and traumas in which e-PMVs are involved should be registered under separate category to provide information for research on safety. If these initial issues will be fixed, there will be solid basis and arguments for improvement of infrastructure and introducing other necessary measures.

There can be additional regulations like the restrictions according to the power of electric assistance. The power of 250-300 W does not give crucial increase of speed and such device can be accepted on the same level as bicycle. When assistance power is increased to $500-750 \mathrm{~W}$ and more the vehicle must be considered on the category of moped or even automobile. Devices with higher power could be banned from sidewalks and bicycle paths and require driving license. Devices with lower power could be used in the same manner as regular bicycle.

There are many attempts to regulate PMV sharing operator companies. This initiative took off from municipalities and such regulations are usually the fines for improperly parked e-PMVs. These measures are becoming common practice, but in the future operator companies also should have obligations to put geo-fencing on dockless e-PMVs in town centers, parks and squares. Until public awareness grows, the private users of PMVs also could be fined for improper riding and parking behavior.

Vandalisation of undocked e-scooters is another yet unresolved issue to deal in upcoming years. It creates many environmentally and socially negative outcomes.

\section{Funding}

This research received no external funding.

\section{Conflicts of interest}

The authors declare no conflict of interest.

\section{References}

Advice, S. L. (2019). Complete guide to e-scooter and pmd laws for singapore riders. https://singaporelegaladvice.com/lawarticles/e-scooter-laws-singapore

AFP. (2019). Trottinettes électriques mal garées à Paris: qui paie l'amende? https://www.lepoint.fr/societe/trottinetteselectriques-mal-garees-a-paris-qui-paie-1-amende-03-08-2019-2328169_23.php

Allen-Munley, C., Daniel, J., \& Dhar, S. (2004). Logistic model for rating urban bicycle route safety. Transportation Research Record: Journal of the Transportation Research Board, 1878(1), 107-115. https://doi.org/10.3141/1878-13

Anderson-Hall, K., Bordenkircher, B., O’Neil, R., \& Scott, S. C. (2019). Governing micro-mobility: a nationwide assessment of electric scooter regulations. Paper presented at the Transportation Research Board $98^{\text {th }}$ Annual Meeting, The National Academies of Sciences, Engineering, and Medicine, Washington, DC, USA.

Aziz, H. A., Nagle, N. N., Morton, A. M., Hilliard, M. R., White, D. A., \& Stewart, R. N. (2018). Exploring the impact of walkbike infrastructure, safety perception, and built-environment on active transportation mode choice: a random parameter model using New York City commuter data. Transportation, 45, 1207-1229. https://doi.org/10.1007/s11116-017-9760-8

Beck, F., Krauß, M., \& Weidenbach, F. (2019). Case: unu GmbH: sharing is caring - a suitable business model for e-scooter in Germany. In Case Studies in Strategic Management (pp. 23-59). Springer. https://doi.org/10.1007/978-3-319-95555-1_3

BerlinOnline. (2019). E-scooter parking banned at Brandenburg gate. https://www.berlin.de/en/news/5859950-5559700-escooter-parking-bans-in-city-centre.en.html

Bernardi, S., La Paix-Puello, L., \& Geurs, K. (2018). Modelling route choice of Dutch cyclists using smartphone data. Journal of Transport and Land Use, 11(1). https://doi.org/10.5198/jtlu.2018.1143

Boniface, K., McKay, M. P., Lucas, R., Shaffer, A., \& Sikka, N. (2011). Serious injuries related to the Segway ${ }^{\circledR}$ personal transporter: a case series. Annals of Emergency Medicine, 57, 370-374. https://doi.org/10.1016/j.annemergmed.2010.06.551

Boss, D., Nelson, T., \& Winters, M. (2018). Monitoring city wide patterns of cycling safety. Accident Analysis \& Prevention, 111, 101-108. https://doi.org/10.1016/j.aap.2017.11.008

Chen, Y., Yan, W., Li, C., Huang, Y., \& Yang, L. (2018). Personalized optimal bicycle trip planning based on Q-learning algorithm. In Proceedings of 2018 IEEE Wireless Communications and Networking Conference (WCNC) (pp. 1-6). https://doi.org/10.1109/WCNC.2018.8377056

Dimitrova, M. (2019). Swedish authorities are looking into possible new rules for e-scooters. https://www.themayor.eu/ga/swedish-authorities-are-looking-into-possible-new-rules-for-e-scooters

Diputació Barcelona. (2019). Ordenança de circulació de vianants $i$ de vehicles. http://cido.diba.cat/normativa_local/3925/ordenanca-de-circulacio-de-vianants-i-de-vehicles-ajuntament-de-barcelona

Ehrgott, M., Wang, J. Y., Raith, A., \& Van Houtte, C. (2012). A bi-objective cyclist route choice model. Transportation Research Part A: Policy and Practice, 46, 652-663. https://doi.org/10.1016/j.tra.2011.11.015 
ePilot Mobility GmbH. (2019). Latest updates in the e scooter regulations. https://epilot.eu/en/blog/latest-updates-in-the-escooter-regulations

Frincu, R., Misso, F. E., \& Repetto, C. (2017). E-light vehicles in European cities: Starting from "Ele. C. Tra.-Electric City Transport" experience, ready to take up new challenges. In Proceedings of 2017 Electric Vehicles International Conference (EV) (pp. 1-6). https://doi.org/10.1109/EV.2017.8242114

Ghanayim, M., \& Bekhor, S. (2018). Modelling bicycle route choice using data from a GPS-assisted household survey. European Journal of Transport and Infrastructure Research, 18.

Gongora, D. A., Baquero, J. J. D., Franco, J. F., \& Mura, I. (2018). Simulation to predict cyclists'exposure to air pollution along bikeways. In Proceedings of 2018 Winter Simulation Conference (WSC) (pp. 2387-2398). https://doi.org/10.1109/WSC.2018.8632358

Gössling, S., Humpe, A., Litman, T., \& Metzler, D. (2019). Effects of perceived traffic risks, noise, and exhaust smells on bicyclist behaviour: An economic evaluation. Sustainability, 11, 408. https://doi.org/10.3390/su11020408

Hardt, C., \& Bogenberger, K. (2019). Usage of e-Scooters in urban environments. Transportation Research Procedia, 37, 155162. https://doi.org/10.1016/j.trpro.2018.12.178

Hasegawa, Y., Dias, C., Iryo-Asano, M., \& Nishiuchi, H. (2018). Modeling pedestrians' subjective danger perception toward personal mobility vehicles. Transportation Research Part F: Traffic Psychology and Behaviour, 56, $256-267$. https://doi.org/10.1016/j.trf.2018.04.016

Howe, E., \& Bock, B. (2018). Global scootersharing market report 2018. InnoZ-Innovation Centre for Mobility and Societal Change.

Jack, D., Pantaleo, N., Smith, C., Yang, Q., Thornburg, J., Kinney, P., \& Chillrud, S. (2018). Using spatially resolved pollution data to plan bicycle infrastructure. Paper presented at the Proceedings of ISEE Conference Abstracts.

Jereb, B., Batkovič, T., Herman, L., Šipek, G., Kovše, Š., Gregorič, A., \& Močnik, G. (2018). Exposure to black carbon during bicycle commuting-alternative route selection. Atmosphere, 9, 21. https://doi.org/10.3390/atmos9010021

John MacArthur, N. K. (2014). Regulations of E-bikes in North America. Portland State University, Transportation Research and Education Center. https://doi.org/10.3141/2468-14

Kang, L., \& Fricker, J. D. (2018). Bicycle-route choice model incorporating distance and perceived risk. Journal of Urban Planning and Development, 144(4), 04018041. https://doi.org/10.1061/(ASCE)UP.1943-5444.0000485

Kim, Y. W., Park, W. B., Cho, J. S., Hyun, S. Y., \& Lee, G. (2018). The new recreational transportation on the street: personal mobility, is it safe? Journal of Trauma and Injury, 31, 125-134. https://doi.org/10.20408/jti.2018.040

King, C. C. S., Liu, M., Patel, S., Goo, T. T., Lim, W. W., \& Toh, H. C. (2019). Injury patterns associated with personal mobility devices and electric bicycles: an analysis from an acute general hospital in Singapore. Singapore Med J, 1, 14.

Krenn, P. J., Oja, P., \& Titze, S. (2015). Development of a bikeability index to assess the bicycle-friendliness of urban environments. Open Journal of Civil Engineering, 5, 451. https://doi.org/10.4236/ojce.2015.54045

Lawrence, B. M., \& Oxley, J. A. (2019). You say one route, we observe four: Using naturalistic observation to understand routechoices in cyclists. Safety Science, 119, 207-213. https://doi.org/10.1016/j.ssci.2019.01.004

Lawrence, M. (2016). Experiential graphic design: generating urban renewal by improving safety and connectivity in bicycle pathways. Kent State University.

Lopez-Garcia, P., \& Nebro, A. J. (2018, May 16-18). Multi-objective design of time-constrained bike routes using bio-inspired meta-heuristics. In Proceedings of Bioinspired Optimization Methods and Their Applications: $8^{\text {th }}$ International Conference, BIOMA 2018, Paris, France.

Luo, J., Boriboonsomsin, K., \& Barth, M. (2020). Consideration of exposure to traffic-related air pollution in bicycle route planning. Journal of Transport \& Health, 16, 100792. https://doi.org/10.1016/j.jth.2019.100792

Madrid. (2019). Ordenanza de movilidad sostenible. https://sede.madrid.es/FrameWork/generacionPDF/ANM2018_45.pdf?idNormativa=5ccdb732cef96610VgnVCM2000001f 4a900aRCRD\&nombreFichero=ANM2018_45\&cacheKey=212

Majumdar, B. B., \& Mitra, S. (2018). Analysis of bicycle route-related improvement strategies for two Indian cities using a stated preference survey. Transport Policy, 63, 176-188. https://doi.org/10.1016/j.tranpol.2017.12.016

Marcus, I. (2019). Excitement and trouble: E-scooter riders invade German cities. https://berlinspectator.com/2019/06/26/excitement-and-trouble-e-scooter-riders-invade-german-cities/

Martínez-Díaz, M., Soriguera, F., \& Pérez, I. (2018). Technology: a necessary but not sufficient condition for future personal mobility. Sustainability, 10(11), 4141. https://doi.org/10.3390/su10114141

Minet, L., Stokes, J., Scott, J., Xu, J., Weichenthal, S., \& Hatzopoulou, M. (2018). Should traffic-related air pollution and noise be considered when designing urban bicycle networks? Transportation Research Part D: Transport and Environment, 65, 736-749. https://doi.org/10.1016/j.trd.2018.10.012

National Conference of State Legislatures. (2020). State electric bicycle laws $\mid$ A legislative primer. http://www.ncsl.org/research/transportation/state-electric-bicycle-laws-a-legislative-primer.aspx

Nocerino, R., Colorni, A., Lia, F., \& Luè, A. (2016). E-bikes and e-scooters for smart logistics: environmental and economic sustainability in pro-E-bike Italian pilots. Transportation Research Procedia, 14, 2362-2371. https://doi.org/10.1016/j.trpro.2016.05.267

Otero, I., Nieuwenhuijsen, M., \& Rojas-Rueda, D. (2018). Health impacts of bike sharing systems in Europe. Environment International, 115, 387-394. https://doi.org/10.1016/j.envint.2018.04.014 
Paris. (2019). Trottinettes électriques: de nouvelles règles de circulation. https://www.paris.fr/pages/trottinettes-electriques-denouvelles-regles-de-circulation-7249

Park, Y., \& Akar, G. (2019). Why do bicyclists take detours? A multilevel regression model using smartphone GPS data. Journal of Transport Geography, 74, 191-200. https://doi.org/10.1016/j.jtrangeo.2018.11.013

Pokorny, P., \& Pitera, K. (2019). Truck-bicycle safety: an overview of methods of study, risk factors and research needs. European Transport Research Review, 11(29), 1-4. https://doi.org/10.1186/s12544-019-0371-7

Prati, G., Marín Puchades, V., De Angelis, M., Fraboni, F., \& Pietrantoni, L. (2018). Factors contributing to bicycle-motorised vehicle collisions: a systematic literature review. Transport Reviews, 38, 184-208. https://doi.org/10.1080/01441647.2017.1314391

Pritchard, R. (2018). Revealed preference methods for studying bicycle route choice - a systematic review. International Journal of Environmental Research and Public Health, 15, 470. https://doi.org/10.3390/ijerph15030470

ReportBuyer. (n.d.). Personal mobility devices market - global industry analysis, size, share, growth, trends, and cycling infrastructure. Transportation Research Part A: Policy and Practice, 111, 252-265. https://doi.org/10.1016/j.tra.2018.03.019

Smith, C. S., \& Schwieterman, J. P. (2018). E-scooter scenarios: evaluating the potential mobility benefits of shared dockless scooters in Chicago.

Tan, A. L., Nadkarni, N., \& Wong, T. H. (2019). The price of personal mobility: burden of injury and mortality from personal mobility devices in Singapore-a nationwide cohort study. BMC Public Health, 19, 1-7. https://doi.org/10.1186/s12889-019-7210-6

Wu, S. J., Lun, L. W., Chan, J.-Y., Yang, L., Wan, I., \& Lin, H.-Y. (2018). Using mobile phones to crowd-source user flow data for assessing bike sharing site suitability. In Proceedings of 2018 IEEE Vehicular Networking Conference (VNC) (pp. 1-2). https://doi.org/10.1109/VNC.2018.8628448

Zagorskas, J., \& Burinskienė, M. (2019). Challenges caused by increased use of e-powered personal mobility vehicles in European cities. Sustainability, 12, 1-13. https://doi.org/10.3390/su12010273

Zalakeviciute, R., Buenaño, A., Sannino, D., \& Rybarczyk, Y. (2018). Urban air pollution mapping based on traffic intensity. Paper presented at the Air Pollution: monitoring, quantification and removal of gases and particles. IntechOpen. https://doi.org/10.5772/intechopen.79570

Zeng, J. (2018). Fostering path of ecological sustainable entrepreneurship within big data network system. International Entrepreneurship and Management Journal, 14, 79-95. https://doi.org/10.1007/s11365-017-0466-3

Zhang, Y., \& Mi, Z. (2018). Environmental benefits of bike sharing: A big data-based analysis. Applied Energy, 220, $296-301$. https://doi.org/10.1016/j.apenergy.2018.03.101

Zhang, Y., Wen, H., Qiu, F., Wang, Z., \& Abbas, H. (2019). iBike: Intelligent public bicycle services assisted by data analytics. Future Generation Computer Systems, 95, 187-197. https://doi.org/10.1016/j.future.2018.12.017

Zuev, D., Tyfield, D., \& Urry, J. (2019). Where is the politics? E-bike mobility in urban China and civilizational government. Environmental Innovation and Societal Transitions, 30, 19-32. https://doi.org/10.1016/j.eist.2018.07.002 